\title{
Risk-based slope monitoring framework
}

\author{
J Armstrong Nevada Gold Mines, USA \\ R Sharon Piteau Associates Ltd., USA \\ C Williams University of Arizona, USA \\ B Ross University of Arizona, USA
}

\begin{abstract}
This paper describes a risk-based slope monitoring framework for open pit mines developed to aid engineers with the design of robust and effective slope monitoring systems. Testing of the framework was implemented at four surface gold mines located in the Carlin trend in Nevada, USA. The framework uses a qualitative approach to assess both the geotechnical conditions as well as the slope design and performance to rate the likelihood of an unwanted geotechnical event for each defined sector of an open pit mine. The likelihood of an event, combined with a consequence rating in alignment with the mine operator's risk standards, is used to define the level of risk per sector. Results from the slope monitoring framework can be used as guidance to select the types of instrumentation that may be utilised to address each level of risk potential.

This process was developed as a collaborative effort between Newmont Corporation, Piteau Associates and the Geotechnical Center of Excellence at the University of Arizona. The risk-based slope monitoring framework is included in the upcoming Guidelines for Slope Performance Monitoring, edited by $R$ Sharon and E Eberhardt, an initiative of the Large Open Pit (LOP) Project.
\end{abstract}

Keywords: slope monitoring, risk management, real-time monitoring, geotechnical, risk-based slope monitoring framework

\section{Introduction}

Slope failures are common occurrences in surface mines. Contributing factors including variability in rock mass properties, geologic structure and porewater pressure can be difficult to fully account for during the design process. This creates a need for effective slope monitoring systems to manage geotechnical risks and keep people safe. In addition to managing risk, effectively implemented slope monitoring systems produce critical information that facilitates the understanding of slope behaviour.

Every mine has unique design challenges, geotechnical conditions, and consequences from failure events. Consequently, the performance monitoring system should be uniquely designed to address the likelihood and consequence of slope failures specific to each mine. In addition, the geotechnical monitoring system should be systematically re-evaluated as conditions change (such as increasing slope height or changes in geologic understanding), or as consequences change (such as adding an underground mine access to the bottom of a pit). Figure 1 provides three examples from the Carlin Trend in Nevada of open pits in different stages of mine life, including a large operating mine (image A), an inactive surface mine hosting an underground access (image $B$ ) and a closed operation (image $C$ ).

The risk-based slope monitoring framework (SMF) described in this paper facilitates the design of appropriate monitoring systems for pit slopes to assess the likelihood and consequence of slope failure. The system described herein applies a standard $5 \times 5$ risk matrix and provides suggestions to guide monitoring system design. Like any qualitative approach, it should be implemented with engineering judgement and common sense. The process is meant to help engineers think through the variables of system design and is not meant to replace detailed review of final monitoring plans by experienced engineers. 

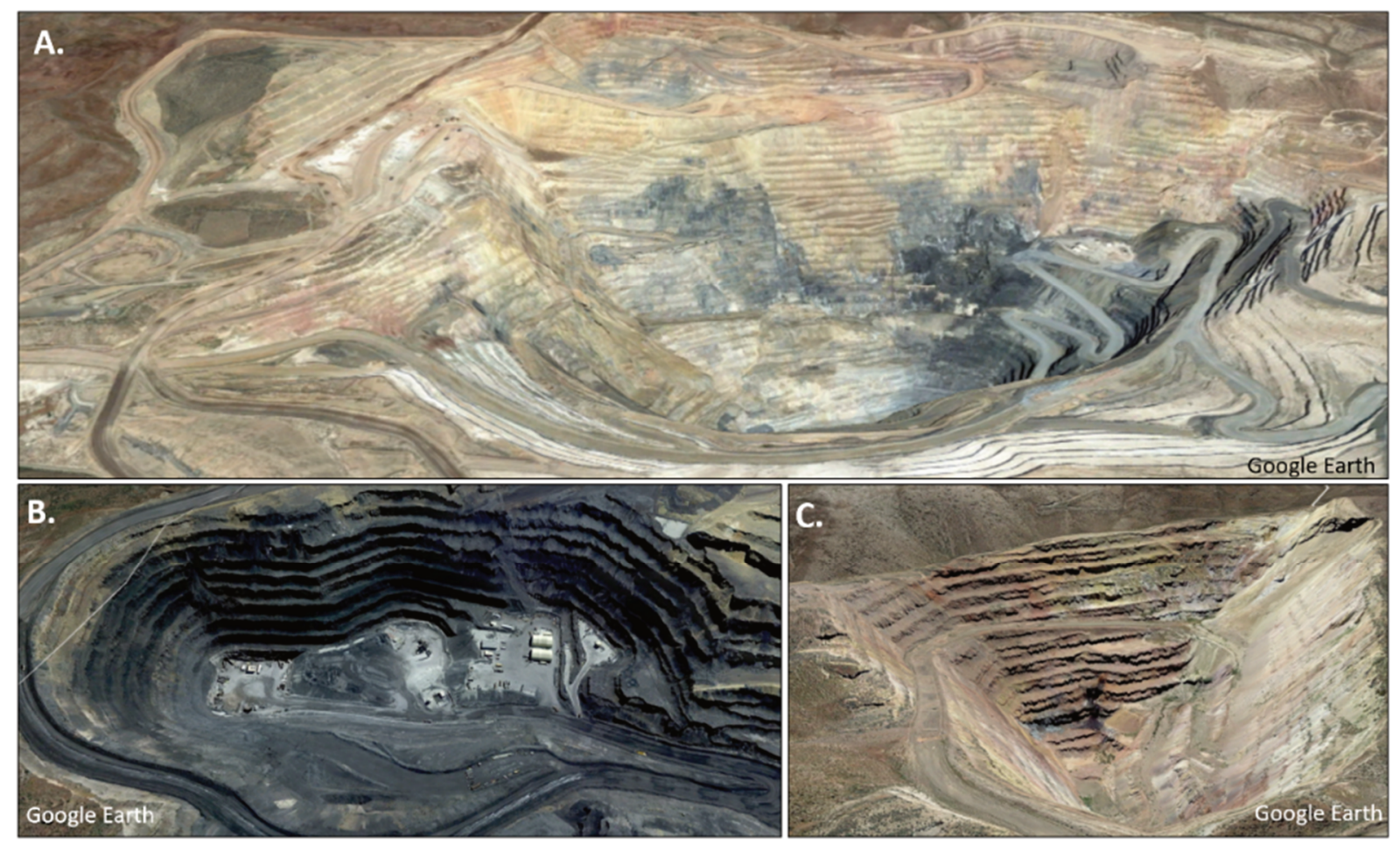

Figure 1 Open pits in the Carlin Trend with contrasting risk potential: (a) Large operating mine, with newly developed slopes; (b) Recently completed open pit used to access an underground mine from the pit floor; and (c) Completed, closed and barricaded open pit

\section{Background}

It was recognised from experience at Newmont's northern Nevada mines that the sites could benefit from a standardised approach to designing slope monitoring systems. In late 2018, Newmont Mining (now Newmont Corporation) approached the Geotechnical Center of Excellence at the University of Arizona regarding development of a process to aid geotechnical engineers in developing monitoring systems for their open pit mining operations. A joint project team was subsequently developed by representatives of Newmont Corporation, The University of Arizona, and Piteau Associates. The project goals, centred on developing monitoring systems, included:

1. Keep employees safe.

2. Achieve company risk management objectives.

3. Protect assets.

4. Protect environment.

5. Maximise safe ore recovery.

After development of the project scope with various stakeholders, it was determined that the monitoring system development process should be:

1. Simple and efficient.

2. Repeatable and reliable.

3. Adequately addresses the residual geotechnical risks of the mine design and development.

4. Easy to communicate to all stakeholders.

5. Able to adapt to, and evolve with, changes in a dynamic mining operation.

6. Able to adapt to changes in slope monitoring and mine development technology. 
By March of 2019, the project team developed a simple spreadsheet-based process and tested the procedure at a large open pit gold mine located in the Carlin Trend near Elko, Nevada, USA. For purposes of testing a formative procedure, factors used to assess specific site conditions, slope design geometry and operational controls were typically weighted equally to avoid subjectivity. The team then revised the process based on field testing. These results were used to calibrate the procedure, at least as it applies to local mining experience. In April 2019, the process was reviewed by 14 industry experts, which led to additional improvements. The resulting modified process was then implemented at three additional operations located in the Carlin Trend. It was determined through this process that equal weighting of most of the natural, design and performance factors produced good results for the subject operations, which constituted a validation exercise. Changing the weighting of individual factors may be required to achieve calibration of the process at operations in different regional settings. Such changes can be accommodated by the SMF process.

While the SMF process remains formative, and has only been applied to operations in the Carlin Trend in Nevada, it is founded on the relevant experience of mining geotechnical practitioners. Some of the key references that influenced this work include those by Hamman (2009), Hawley et al. (2009), de Graaf \& Wessels $(2013,2015,2016)$, Hawley \& Cunning (2017) and Rose et al. (2018). The SMF process is also introduced in the upcoming Guidelines for Slope Performance Monitoring.

\section{Methodology}

The SMF process addresses both known hazards and potential hazards in open pit mines. Known hazards include current and historic slope failures that have affected the mining operation. Potential hazards, such as failure mechanisms identified during the slope design process, have not yet been realised. Slope monitoring systems should provide adequate surveillance to manage the known hazards as well as address potential hazards that may arise in the future.

The SMF process uses three steps to address known and potential slope hazards:

1. Assess risks associated with known hazards.

2. Assess risks associated with potential hazards.

3. Develop a monitoring plan based on both known and potential hazards.

The full SMF process is contained in a spreadsheet format. A high-level summary of the process is presented herein; however, a step-by-step description is beyond the scope and size limitations of this paper.

\subsection{Risk assessment of known hazards}

Known geotechnical hazards that have a reasonable likelihood of affecting a mining operation are commonly tracked on hazard maps and geotechnical risk registers. For known hazards, geotechnical personnel typically have a good understanding of the failure mechanism, the likelihood of additional events, and the potential consequences to the mine. Thus, with the aid of the operation's risk matrix, engineers should be able to qualitatively rank the likelihood and consequence of known hazards as low, moderate, high, or critical. After known hazards have been ranked, a map of the open pit can be developed to represent the risk. A hypothetical example of this type of map is shown in image A of Figure 2. The colour of the dot represents the level of risk, with green representing a low risk, yellow representing a moderate risk, orange representing a high risk and red representing a critical risk. The known hazards in an open pit are important to investigate, understand, and document, because similar failure mechanisms may be repeated on future cutbacks. 

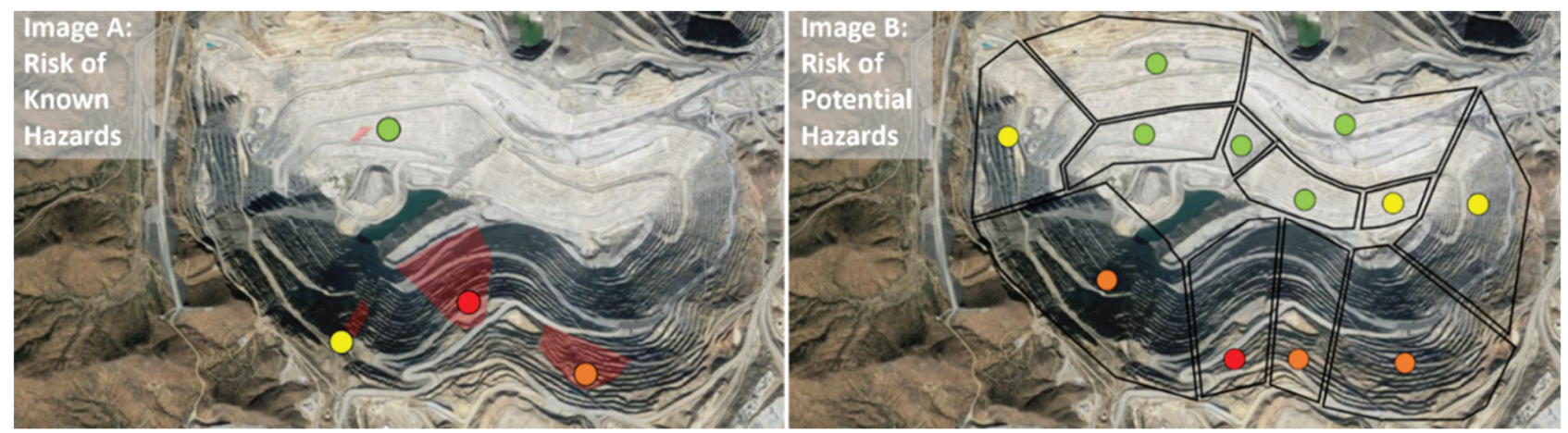

Figure 2 Hypothetical example of open pit maps documenting the location and risk level of known and potential slope hazards

\subsection{Risk assessment of potential hazards}

Assigning risk to potential hazards can be challenging as they have not yet been realised; therefore, the following process is suggested for identifying and assigning risk to potential hazards:

1. Divide the open pit into logical slope monitoring sectors, based upon factors such as geologic, hydrogeologic and geotechnical characteristics, development performance, mine design, pit geometry, mining method, and mine development sequencing.

2. Rate the likelihood of failure for each sector using the slope stability rating system (refer to Section 3.2.2).

3. Document the failure mechanisms and rate the associated consequence of failure for each sector using company-specific criteria.

4. Combine likelihood and consequence of slope failure to define risk ranking per monitoring sector.

Once risk rankings are known for each monitoring sector, the rankings can be presented on a map as an input to the slope monitoring plan. Similar to the known hazards, a hypothetical example is shown as a plan view map in image B of Figure 2.

\subsubsection{Slope monitoring sectors}

Geotechnical data and reports should be compiled and reviewed before developing a slope monitoring plan. Once this is complete, geotechnical monitoring sectors can be developed based on the following criteria:

- Geological and geotechnical considerations:

- Structural control (faults).

- Geologic contacts, alteration, or major changes in rock mass properties.

- Adversely oriented rock fabric.

- Areas where the rock strength may degrade over time.

- Areas where pore pressures may be critical to slope stability.

- Areas with unique wall performance (both positive and negative).

- Mine design considerations:

- Slope geometry (bench face, inter-ramp, and overall angles).

- Bench configurations (single, double, or triple batter).

- Slope shape and confinement (concave or convex).

- Mine development sequencing (service life of slope). 
- Mine access (permanent verse temporary).

- Major and permanent infrastructure.

- Line-of-sight limitations of possible geotechnical equipment.

In greenfield projects, slope performance data will most likely not be available. In brownfield projects, the performance of previous mining cuts should be considered.

\subsubsection{Slope stability rating system (likelihood)}

A slope stability rating system (SSRS) was developed as a component of the SMF process to qualitatively rate the likelihood of an unwanted geotechnical event in a given monitoring sector. The SSRS is used to rate the geotechnical conditions, the design that addresses those conditions, the practices used to implement the design and the performance of the rock slope. It uses a similar framework as the waste dump and stockpile stability rating and hazards classification system described in Hawley \& Cunning (2017) adapted to incorporate the critical aspects of rock slopes. The SSRS tool has two main components: the geotechnical conditions index $(\mathrm{GCl})$ and the design, performance, and implementation index (DPI).

\subsubsection{Geotechnical conditions index (GCl)}

The $\mathrm{GCl}$ is a measure of the conditions that can affect the stability of a rock slope. The $\mathrm{GCl}$ component of the SMF spreadsheet has two main sections. The first section addresses aspects of rock strength, structure, and regional stress; and the second section addresses surface water and pore pressure conditions. Each factor is rated from an unfavourable to a favourable condition depending on characteristics of each open pit sector. Each factor has a description to guide the user for appropriate selection. If it is determined that a factor is not relevant to the evaluated sector, the factor can be toggled on or off in the system.

\subsubsection{Design, performance, and implementation index (DPI)}

The DPI is a measure of the factors that the mining operation can use to control slope stability. These factors include:

- How well the natural conditions that influence slope stability are understood, such as pore pressure, rock mass strength and structural features.

- How challenges/conditions are addressed in the mine design.

- How well the mine plan is being implemented.

- How well the slopes are performing.

The DPI component contains three main sections, including surface and groundwater controls, slope design, and slope performance and operational factors. Design and performance parameters that are not relevant to an evaluated open pit sector can also be toggled on and off in the system. As with the $\mathrm{GCl}$ described above, each of these factors are rated from unfavourable to favourable.

The SSRS is a summation of the GCl and DPI scores, used to estimate a qualitative rating of a likelihood for input into a $5 \times 5$ risk matrix, where a low score is indicative of a higher likelihood of a geotechnical event. A score below 20 would be placed in the very high likelihood class. A score of 20-40, 40-60, 60-80, and $80-100$, would be placed in a high, moderate, low, and very low likelihood classification respectively.

\subsubsection{Determination of consequence}

The risk-based monitoring framework, as with most risk-based systems, utilises likelihood and consequence to assess the level of risk potential. As previously discussed, the likelihood of a slope failure is qualitatively estimated by the SSRS. The next step is to determine the consequence of failure. The intent of the consequence rating is specific to each company's definition of risk tolerance. Therefore, the company's 
consequence classifications should be utilised for rating the potential consequence determined by the SMF process for each monitoring sector of the open pit.

Before a consequence is assigned, geotechnical engineers should assess the predicted slope condition and determine the most reasonable mechanism of failure. The scale of failure types and possible runout impacts should also be considered when determining the consequence of failure. The failure mechanisms per monitoring sector should be documented in as much detail as possible for input to the monitoring plans.

As with most mining risk-based systems, several factors should be considered when assigning consequence ratings, in the event that a geotechnical event occurs within any sector. For each of these factors, a consequence rating is assigned that ranges from 1 (lowest consequence) to 5 (highest consequence) for each sector. A typical consequence system defines consequence ratings as: 1 - minor, 2 - moderate, 3 - major, 4 - serious, and 5 - catastrophic. Typical consequence factors include, but are not limited to, the potential impacts that can reasonably occur in the following areas:

- Health and safety: potential for multiple fatalities, a single fatality, or serious injury.

- Cash flow: potential impact to income resulting from the loss of equipment, ramps, reserves and production.

- Infrastructure: potential impact from the loss of portals for underground mines, power systems, dewatering systems (wells, drainage galleries etc.) and buildings.

- Environmental: potential impact to surface and groundwater, air quality, and wildlife.

- Community and reputation: potential impact to communities, local economies and perceptions of the company, and licence to operate.

Each factor listed above should be assigned a consequence rating for each sector. The maximum reasonable consequence is suggested to be selected for the input to the monitoring plan. For example, if the health and safety factor is rated 4 (serious level consequence) for one sector and the other four factors in that sector are rated 3 (major level consequence), the user should apply the higher consequence factor thus selecting an overall factor rating of 4 for the sector.

\subsubsection{Determination of risk level}

Once the likelihood and consequence are estimated for each monitoring sector, a $5 \times 5$ risk matrix provides an example for determination of the level of risk. During the initial research phase for this project, it was found that the differences in $5 \times 5$ risk matrices between mining companies are subjective. This is most likely linked to the differences in defining the likelihood and material consequences developed by each mining company. Thus, it is recommended to use the same $5 \times 5$ risk matrix that is paired to the company's consequence rating. A generic $5 \times 5$ risk matrix is presented in Table 1. For an example, the black dot represents a sector that would have a likelihood rating of 3 and consequence rating of 3 .

Table $1 \quad$ Generic $5 \times 5$ risk matrix

\begin{tabular}{|c|c|c|c|c|c|c|}
\hline & & \multicolumn{5}{|c|}{ Consequence } \\
\hline & & 1 & 2 & 3 & 4 & 5 \\
\hline \multirow{5}{*}{ 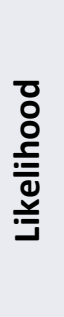 } & 5 & High & High & Critical & Critical & Critical \\
\hline & 4 & Moderate & High & High & Critical & Critical \\
\hline & 3 & Low & Moderate & High & High & Critical \\
\hline & 2 & Low & Low & Moderate & High & High \\
\hline & 1 & Low & Low & Low & Moderate & High \\
\hline
\end{tabular}




\subsection{Considerations for designing a slope monitoring system}

The SMF process provides general guidance on monitoring system design and suggested levels of redundancy based on risk per monitoring sector. It also provides general guidance on frequency of alarming and inspection. The guidance is not meant to be prescriptive, and there are cases that have been successful with more and less monitoring in place. The guidance is meant to be aligned with industry average approaches; thus, it is expected that the process will evolve with experience. The suggested monitoring framework provided by the SMF process is summarised in Table 2, based on the following considerations:

- Design of a monitoring system is based on an understanding of the potential failure mechanism and is used to assist interpretation of the mechanism, track movements, and alert personnel in the event of an incipient failure.

- Monitoring instruments that take measurements and transmit data in real-time are appropriate for alarming in moderate to critical risk rated sectors.

- Monitoring instruments that are not real-time are often necessary for identifying and understanding failure mechanisms, as well as assessing the nature of longer-term trends.

- Monitoring instruments such as radar, laser scanners, and photogrammetry can monitor large areas and provide an overall understanding of the movement of a failure mass.

- Geodetic and line-of-sight monitoring instruments can provide critical information to validate data from other instrumentation.

- The required frequency of measurements increases as the risk increases.

- Visual inspections assist the interpretation, validation, and reporting on monitoring data. They are an important component of the risk management process that ensures the monitoring system is working as-designed.

Table 2 Monitoring suggestions and frequency based on risk

\begin{tabular}{|c|c|c|c|c|}
\hline & \multicolumn{4}{|c|}{ Monitoring suggestions } \\
\hline & Low risk & Moderate risk & High risk & Critical risk \\
\hline & $\begin{array}{l}\text { - Data validated } \\
\text { and reviewed by } \\
\text { engineer }\end{array}$ & $\begin{array}{l}\text { - Data validated } \\
\text { and reviewed by } \\
\text { engineer daily }\end{array}$ & $\begin{array}{l}\text { - Data validated } \\
\text { and reviewed by } \\
\text { engineer each shift }\end{array}$ & $\begin{array}{l}\text { - Data validated and } \\
\text { reviewed by engineer } \\
\text { each shift }\end{array}$ \\
\hline & weekly/monthly & $\begin{array}{l}\text { - Consider real-time } \\
\text { monitoring system } \\
\text { with appropriate } \\
\text { alarms }\end{array}$ & $\begin{array}{l}\text { - Consider one or } \\
\text { more real-time } \\
\text { monitoring systems } \\
\text { with appropriate } \\
\text { alarms }\end{array}$ & $\begin{array}{l}\text { - Consider multiple } \\
\text { real-time monitoring } \\
\text { systems with } \\
\text { appropriate alarms (at } \\
\text { least one wide area } \\
\text { coverage system) }\end{array}$ \\
\hline & \multicolumn{4}{|c|}{ Monitoring frequency } \\
\hline & Low risk & Moderate risk & High risk & Critical risk \\
\hline Alarming & As needed & Checked daily & $\begin{array}{l}\text { Per shift; consider } \\
\text { real-time alarming }\end{array}$ & $\begin{array}{l}\text { Per shift to real-time } \\
\text { alarming }\end{array}$ \\
\hline $\begin{array}{l}\text { Visual } \\
\text { inspections }\end{array}$ & Weekly & Daily & Per shift & $\begin{array}{l}\text { Per shift to constant } \\
\text { (with spotter if } \\
\text { needed) }\end{array}$ \\
\hline Reporting & Monthly & Weekly/monthly & Daily/weekly & Daily \\
\hline
\end{tabular}


The slope engineer should apply experience and knowledge of the mine's geotechnical conditions and the types of instruments that are available to build and then systematically maintain, and evolve the monitoring system. Ultimately, the monitoring plan should address:

- Known and potential hazards (understanding the potential failure mechanisms).

- Potential failure modes and associated speed of failure development (brittle versus ductile).

- The evolution of the mine plan.

- The ability to cross-validate data to ensure reliability.

\section{$4 \quad$ Case study}

\subsection{Background}

The SMF process was trialled at four open pits managed by a Nevada, USA gold mining operation. Results were used to improve and complete the SMF process and provide validation for application of improving and optimising the slope performance monitoring system for each open pit. Two of these open pits were being actively mined and two were inactive pits that hosted portals to active underground mining operations. The SMF process returned a high risk for one of the open pits (which will be referred to as Pit 1). The high risk ranking was not initially obvious, due to the pit being in an early stage of development. In this case, the operation had initially anticipated a medium risk ranking. For this reason, Pit 1 is the focus of this case study.

Pit 1 is in the first phase of expansion within a historic mining district. Planned slopes expose faulted and folded metasedimentary and carbonate rocks of Devonian and Ordovician age with mostly poor to fair rock mass quality. Highwalls in this pit are generally depressurised.

At the time of writing (October 2019), an interim and final layback were being actively mined. Figure 3 is a view of the south wall of Pit 1 at the time of the assessment in April 2019. New mining on the interim layback was at the 5520 level, and mining of the final layback had not yet been initiated when the SMF process was applied to characterise the risks. Note that new mining was restricted to levels below the 5600 level truck queue, as the benches above the 5600 level were mined with previous cutbacks.

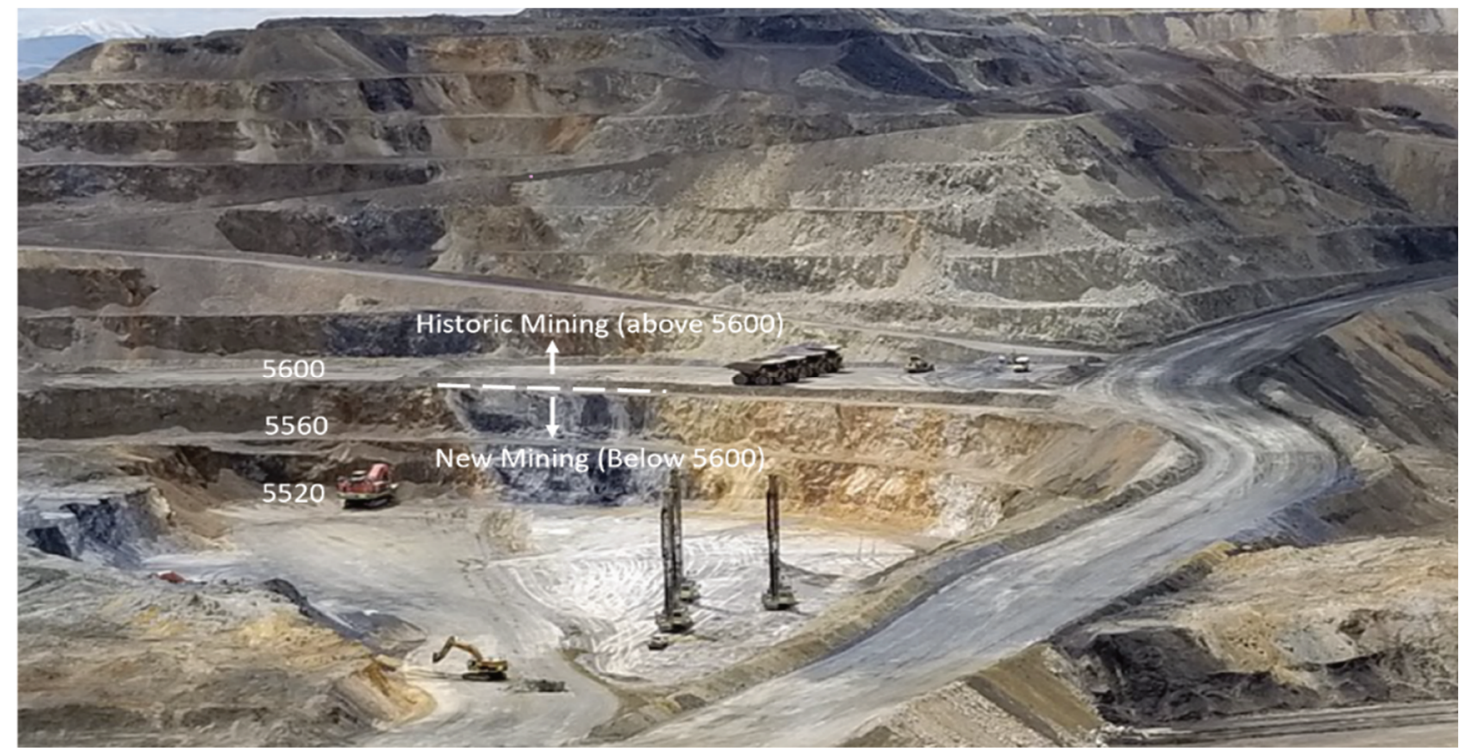

Figure 3 Pit 1 interim layback looking south, April 2019

Pit 1 is a deposit of significant size and importance in the early stage of development. The SMF process was used to assist with the design of the monitoring system concurrent with excavation of the first few benches. The Pit 1 interim cutback was divided into four monitoring sectors (N, E, S and W) as shown in Figure 4. 
Each monitoring sector has similar geotechnical and design-risk components, except for the east sector, which is designed to have a relatively limited height of less than four benches. Therefore, to simplify the selection of an appropriate monitoring system, the $\mathrm{GCl}$ and DPI components for the $\mathrm{N}, \mathrm{S}$, and $\mathrm{W}$ sectors were combined and used to represent the entire pit. In larger pits with a high degree of geotechnical variability, it may be appropriate to evaluate monitoring sectors separately.

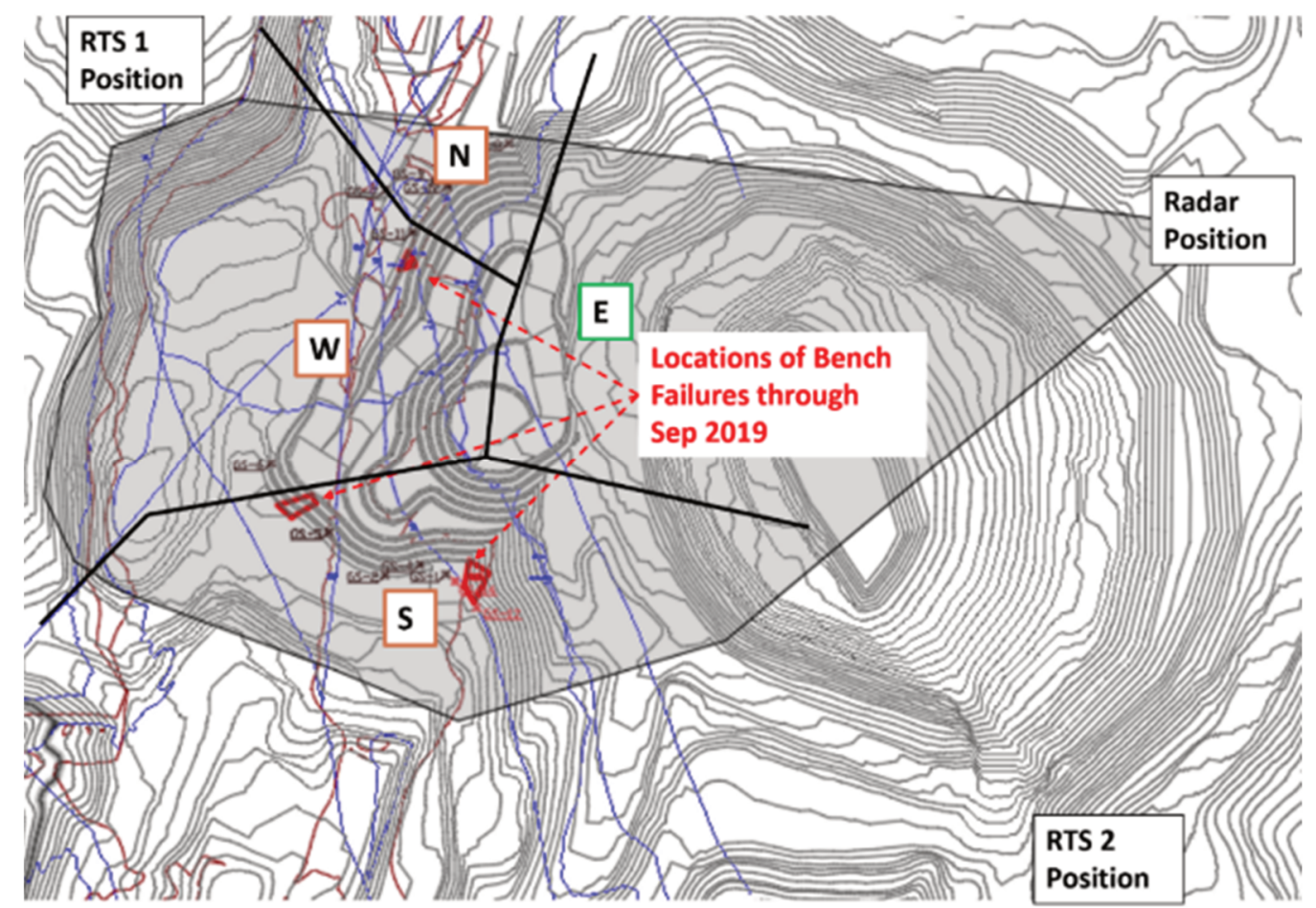

Figure 4 Locations of monitoring sectors, robotic total stations (RTS) and radar instruments, and bench-scale instabilities

\subsection{Application of the SSRS for Pit 1}

The SSRS was applied by using the $\mathrm{GCl}$ and the DPI.

The $\mathrm{GCl}$ inputs were influenced by the following factors:

- Mine development was accelerated relative to the original schedule; therefore, limited geotechnical investigation was available for design.

- Structural domains were not characterised for the interim layback.

- Generally arid conditions; therefore, surface water control is only seasonally significant.

- Regional water table is below the mining level; however, perched and compartmentalised water can occur locally.

- Limited piezometric data in proximity of the pit walls to confirm groundwater pressure distribution.

- Geotechnical drilling that indicated the majority of rock mass quality to be poor to fair (majority $\mathrm{RMR}_{76}$ ranging from 25 to 50 ).

- Previous mining in the area incurred a high level of blast damage to the highwalls; therefore, similar results are anticipated for new mining.

These factors resulted in a scaled $\mathrm{GCl}$ score of 28 as summarised in Table 3, including the scores and descriptions for the $\mathrm{GCl}$ rating for Pit 1 . Since the scoring is variable, based on the factors that are relevant to a specific property or slope, the $\mathrm{GCl}$ is scaled to a total possible score of 50 . 
Table 3 Scores and descriptions for $\mathrm{GCl}$ rating for Pit 1

\begin{tabular}{|c|c|c|}
\hline \multicolumn{3}{|l|}{ Geotechnical Conditions Index (GCI) } \\
\hline Category & $\begin{array}{l}\text { Assigned score } \\
\text { (out of 10) }\end{array}$ & Description \\
\hline \multicolumn{3}{|c|}{ Ground and surface water conditions - factors and ratings } \\
\hline Precipitation & 7.5 & $\begin{array}{l}\text { Low annual precipitation; } 4-15 \text { inches }(10-35 \mathrm{~cm}) \\
\text { annually }\end{array}$ \\
\hline Surface water & 7.5 & $\begin{array}{l}\text { Favourable conditions; minimal surface water draining } \\
\text { into pit }\end{array}$ \\
\hline Regional water table & 8.0 & $\begin{array}{l}\text { Favourable conditions; mining level above-ground } \\
\text { water table }\end{array}$ \\
\hline Perched groundwater systems & NA & \\
\hline $\begin{array}{l}\text { Permeability of rock mass and } \\
\text { structure }\end{array}$ & 7.5 & $\begin{array}{l}\text { Favourable conditions; depressurisation achieved by } \\
\text { minimal efforts }\end{array}$ \\
\hline Recharge potential & 5.0 & Moderate conditions \\
\hline \multicolumn{3}{|c|}{ Rock mass and structure conditions - factors and ratings } \\
\hline Intact rock strength & 3.5 & $\begin{array}{l}\text { Mostly moderate to locally weak conditions; moderate } \\
\text { rock strength, R3, unconfined compressive strength } \\
25-50 \mathrm{MPa}\end{array}$ \\
\hline Rock mass strength & 3.0 & $\begin{array}{l}\text { Mostly poor to moderate conditions; locally poor to } \\
\text { moderately fractured; locally highly altered, GSI } 20-50\end{array}$ \\
\hline Rock mass damage & 2.5 & Poor conditions; limited control of blast damage \\
\hline Rock mass deterioration & 7.5 & $\begin{array}{l}\text { Favourable conditions; minimal deterioration over } \\
\text { expected mine life }\end{array}$ \\
\hline $\begin{array}{l}\text { Rock mass fabric and anisotropic } \\
\text { strength }\end{array}$ & 5.0 & $\begin{array}{l}\text { Moderate conditions; moderate to adversely oriented } \\
\text { joints; minor toppling in south wall; mostly moderate } \\
\text { shear strength of joints. }\end{array}$ \\
\hline In situ stress conditions & NA & $\begin{array}{l}\text { Shallow pit; stress not deemed to be a significant } \\
\text { factor }\end{array}$ \\
\hline Geologic complexity & 3.5 & $\begin{array}{l}\text { Moderately to highly complex geology; however, well } \\
\text { studied. Complex thrust system adds complexity to } \\
\text { structural model }\end{array}$ \\
\hline Total score & 60.5 & \\
\hline Total possible points (less N/A) & 110 & \\
\hline $\mathrm{GCl}$ percentage & $55 \%$ & \\
\hline Scaled GCI (max 50) & 28 & \\
\hline
\end{tabular}

The DPI inputs for Pit 1 considered the following general design and operational conditions:

- Slope heights will be between 100 and 300 metres.

- Structural domains were not defined for slope design of the interim pit.

- No kinematic assessments were performed for the interim or final pit. 
- The level of staffing of geotechnical and geology personnel at the time of the assessment was considered to be insufficient to perform thorough geology/hydrogeology and design reconciliation.

- At the time of the SSRS assessment, slope modelling was not yet performed for the interim or final pit.

- Previous mining in the area incurred a high level of blast damage to the highwalls; similar results are expected for new mining.

Table 4 summarises the inputs and scores that were assigned for the DPI; Pit 1 received a scaled DPI rating of 22.

Table $4 \quad$ DPI scoring summary for Pit 1

\begin{tabular}{|c|c|c|}
\hline \multicolumn{3}{|l|}{ Design Performance Index (DPI) } \\
\hline Category & $\begin{array}{l}\text { Assigned score } \\
\text { (out of 10) }\end{array}$ & Description \\
\hline \multicolumn{3}{|c|}{ Ground and surface water controls, monitoring, and reconciliation - factors and ratings } \\
\hline Surface water controls & 5.0 & $\begin{array}{l}\text { Controls believed to be generally effective; however, } \\
\text { have not yet been verified }\end{array}$ \\
\hline Depressurisation measures & NA & Not considered significant for this pit \\
\hline Pore pressure measurement & NA & $\begin{array}{l}\text { Not well known; however, not considered significant } \\
\text { for this pit }\end{array}$ \\
\hline Hydrogeological study & NA & $\begin{array}{l}\text { Regional hydrogeology understood, not considered } \\
\text { significant for this pit }\end{array}$ \\
\hline $\begin{array}{l}\text { Pore pressure targets and } \\
\text { reconciliation }\end{array}$ & NA & No targets \\
\hline \multicolumn{3}{|l|}{ Slope design - factors and ratings } \\
\hline Slope height & 8.0 & $\begin{array}{l}\text { Favourable conditions - slope height between } 300 \text { and } \\
1,000 \text { feet }(100 \text { and } 300 \mathrm{~m})\end{array}$ \\
\hline Slope shape (confinement) & 9.0 & Very favourable conditions, tight curved slopes \\
\hline Stability analysis & 4.5 & Limited geotechnical modelling \\
\hline Design flexibility & 5.0 & Moderate design flexibility \\
\hline \multicolumn{3}{|c|}{ Slope performance and operational controls - factors and ratings } \\
\hline Controlled blasting & 2.5 & Limited controlled blasting \\
\hline Sinking rate & 2.5 & Fast sinking rate-approximately one bench per month \\
\hline Wall performance & 10.0 & Expected to have stable walls \\
\hline Phase of excavation & 5.0 & Walls being actively mined or recently completed \\
\hline $\begin{array}{l}\text { Design reconciliation and } \\
\text { verification }\end{array}$ & 5.0 & $\begin{array}{l}\text { Design reconciliation generally pursued; toe/crest } \\
\text { compliance; sporadic geology mapping }\end{array}$ \\
\hline Total score & 49 & \\
\hline Total possible points (less N/A) & 110 & \\
\hline DPI percentage & $45 \%$ & \\
\hline Scaled GCI $(\max 50)$ & 22 & \\
\hline
\end{tabular}


The likelihood rating is determined from the SSRS which is the sum of the GCI (28) and DPI (22). The rock slope stability rating which is a sum of the $\mathrm{GCl}$ and DPI is equal to 50 . The corresponding likelihood rating for Pit 1 was determined to be 3 , which equates to a moderate likelihood for a geotechnical event.

Considering the expected geology, moderate slope heights, and maximum inter-ramp angle of $42^{\circ}$, the maximum reasonable geotechnical event expected while mining Pit 1 is anticipated to be a multiple bench instability. Risk exposure levels for a multiple bench instability, given below in Table 5, were rated for each of the above consequence categories with respect to the mine operator's risk ranking matrix.

Table 5 Assigned consequence table

\begin{tabular}{|c|c|c|}
\hline \multicolumn{3}{|c|}{ Maximum reasonable event: multiple bench instability } \\
\hline Category & Score & Description \\
\hline Health and safety & 3 & $\begin{array}{l}\text { Single person spends some time in hazard zone defined by } \\
\text { maximum reasonable event }\end{array}$ \\
\hline Cash flow impact & 3 & $\begin{array}{l}\text { Loss or delay of ore from multiple-bench scale instability (value } \\
\text { confidential) }\end{array}$ \\
\hline Loss of asset valuation & 2 & (value confidential) \\
\hline Environmental & 1 & No impact or very low environmental impact \\
\hline Community and reputation & 1 & A few sporadic complaints \\
\hline Maximum consequence & 3 & \\
\hline
\end{tabular}

The monitoring guidance risk class is a function of both the likelihood and consequence ratings using the matrix shown in Table 1. Based on a likelihood rating of 3 and a consequence rating of 3 , the monitoring guidance risk class for Pit 1 is classified as high risk.

\subsection{Selection of monitoring instrumentation for Pit 1}

The SMF process was utilised to provide guidance for instrumentation selection and monitoring frequency appropriate for an interpreted high risk classification, as per Table 2. The actual monitoring instrumentation and inspection program selected by the mine site geotechnical team included the following:

- Two robotic total stations (RTS) monitoring prisms (real-time monitoring).

- One ground-based radar (real-time monitoring).

- Crack meters as appropriate, determined by geotechnical personnel.

- Periodic laser scans and photogrammetry surveys.

- Daily visual inspections by geotechnical personnel.

- Daily reporting when working near an active instability, weekly reporting of slope performance, and monthly reporting of monitoring and slope performance.

The monitoring program implemented by the operator differed slightly from the monitoring suggestions provided by the SMF process for a high risk classification. Monitoring data were not validated by an engineer each shift, as per the monitoring frequency guidance listed in Table 2, but only during the day shifts when geotechnical engineers were scheduled to be onsite. The operator considered this level of data review to be sufficient, as slope monitoring radar data were viewed in real-time at the mine dispatch office in active mining areas, and geotechnical and dispatch personnel received electronic notifications (emails and text messages) of prism and radar alarms. 
Referring to Figure 4 for locations in the mine area, it should be noted that only RTS 1 providing prism monitoring of the south highwall, was operating when the SSRS assessment was being performed. RTS 2 was not added until after the first bench was mined; and the radar was not deployed until July 2019, after the first three to four benches were mined.

\subsection{Slope performance}

During June 2019, following completion of the SMF assessment, three separate bench-scale instabilities occurred on the west and south walls of Pit 1 . The first two instabilities were relatively minor; however, the third instability continued to develop over the span of several months, eventually reaching a slope height of about $40 \mathrm{~m}$. The locations of the instabilities with respect to the RTS and radar locations are shown in Figure 4.

The first slope instability occurred on 8 June 2019 on the west highwall prior to the deployment of the radar and was not detected in advance by prism monitoring. Post-failure monitoring included UAV photogrammetry, laser scanning, and deployment of a survey prism on the back scarp.

The second slope instability occurred on 21 June on the southwest highwall prior to the deployment of the radar, but was detected by prism monitoring prior to failure. A photo of this instability and its relative location in the pit are shown in Figure 5. A time-series graph of relevant prism movement leading up to the failure event is shown in Figure 6. Post-failure monitoring included UAV photogrammetry, laser scanning, and deployment of a survey prism and crack monitors on the back scarp.

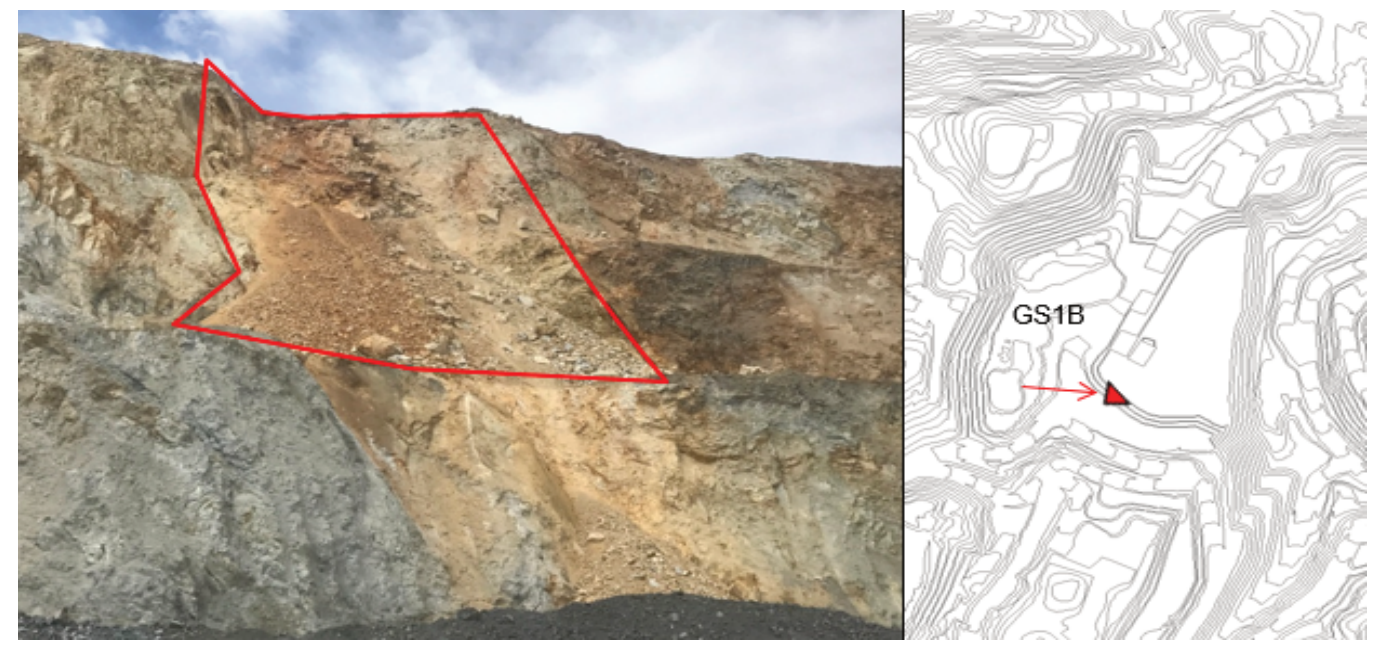

Figure $5 \quad 21$ June bench-scale instability on the southwest highwall

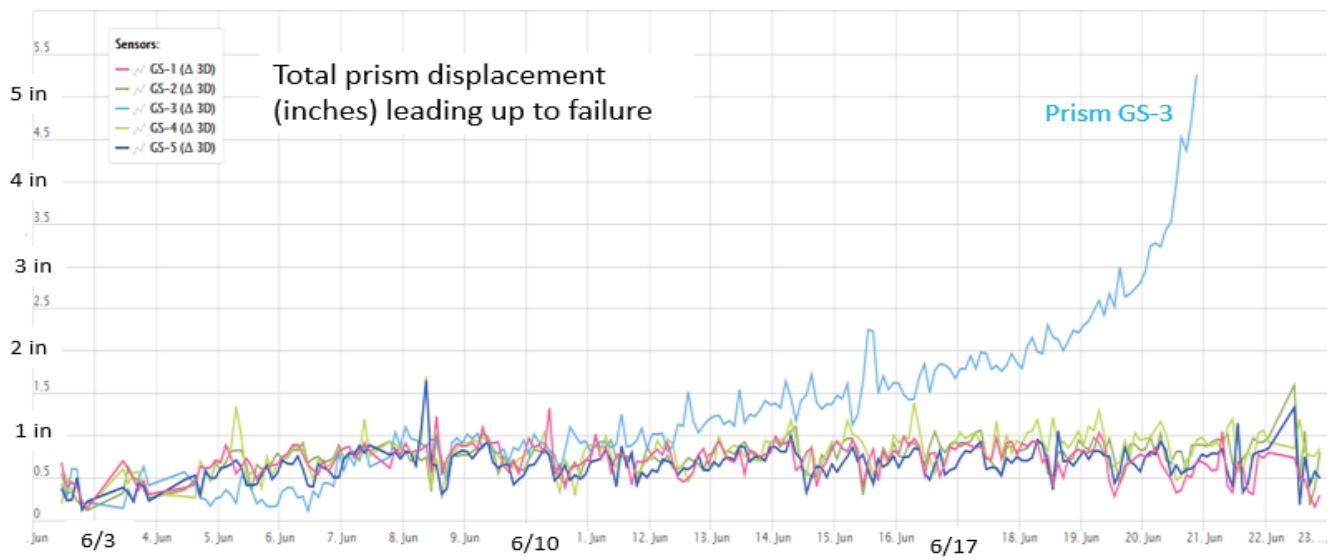

Figure 6 Time-series graph of prism data showing prism GS-3 located at crest of the 21 June wedge failure; the $y$-axis scale is in inches 
A third slope instability began on 20 June 2019 as small-scale sloughing on the southeast highwall prior to deployment of the radar and continued to ravel over the next six weeks. On 5 August 2019, the deformation zone accelerated and increased in size to three benches immediately following a trim blast at the toe level (5480-5440 trim). The slope acceleration following the trim blast was successfully detected by both radar and prism monitoring prior to the benches failing, allowing the operator to update safety protocols for working near the hazard zone. Post-failure monitoring included UAV photogrammetry, laser scanning, and deployment of survey prisms and crack monitors on the back scarp. A geotechnical status report issued by the geotechnical team on 7 August, which includes a screenshot of the radar data showing slope acceleration following the trim shot, is shown in Figure 7.

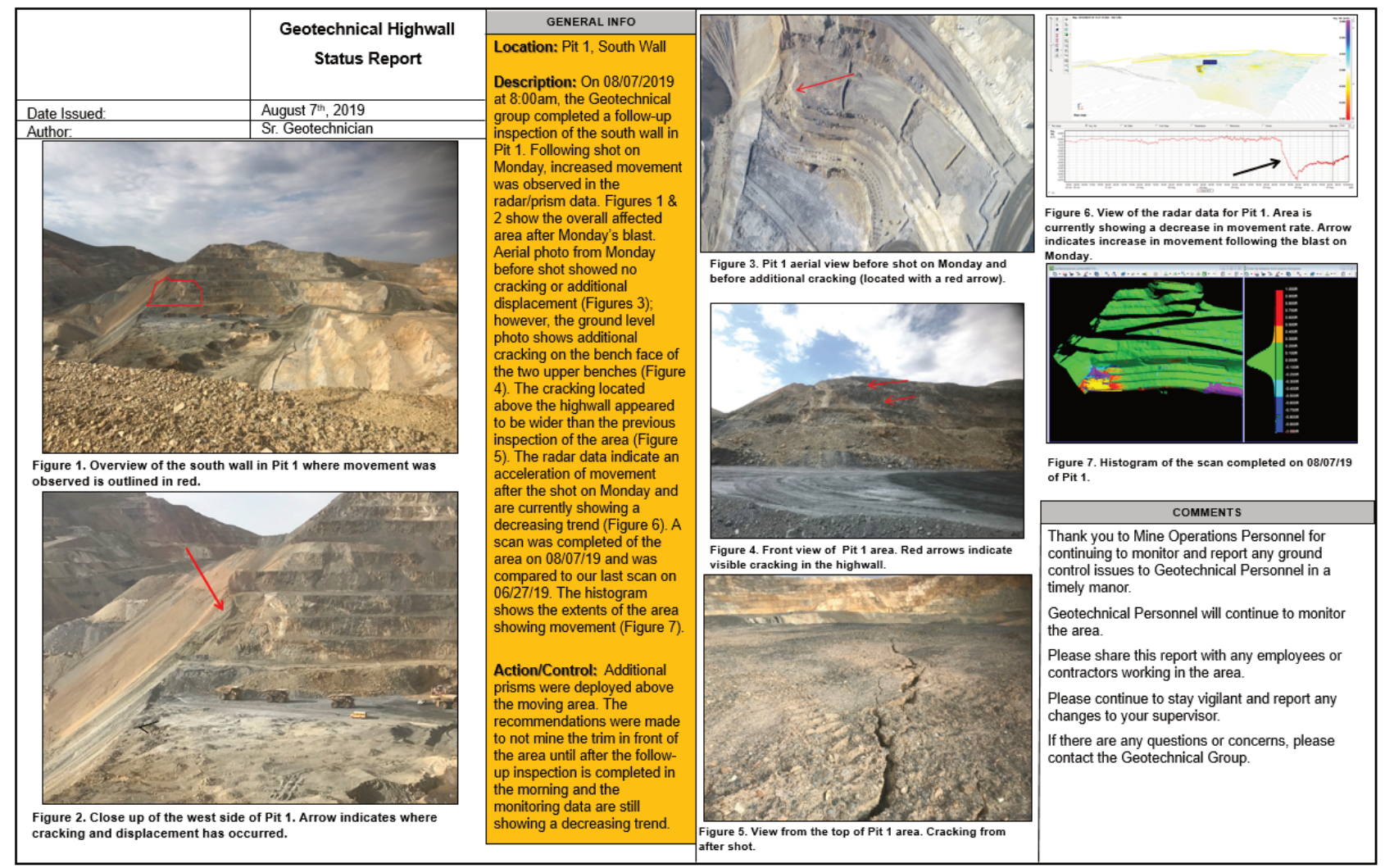

Figure 7

Geotechnical status report for 7 August

This section of the southeast highwall continued to deform at a rate approaching $300 \mathrm{~mm} / \mathrm{d}$ until the wall was regraded by dozer to a slope angle of $23^{\circ}$. Figure 8 is a view of the southeast wall in September 2019, following dozer remediation of the triple-bench instability. Radar monitoring with a TARP alarming protocol ensured the dozer remediation work was performed with minimal risk potential. Subsequent back analyses indicated the instability, which appeared to be triggered by the trim blast at the failure toe, was controlled by an altered lithology contact that was not properly characterised in the geotechnical model. 


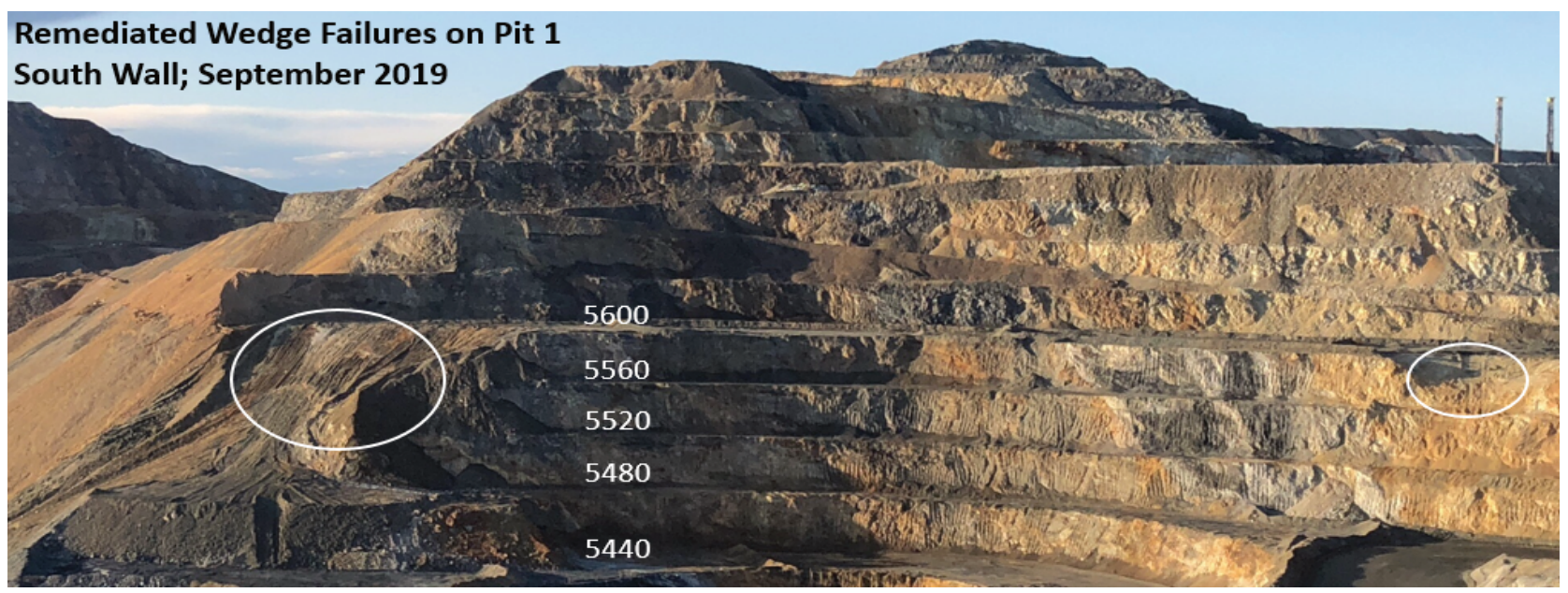

Figure $8 \quad$ View of remediated slope failures on south highwall

In summary, the SMF high risk classification for Pit 1 appears to be appropriate based on the number and frequency of slope instabilities that occurred while mining the first five benches. It is noteworthy that slope movement leading up to the first instability was not detected when only one real-time monitoring system (a single RTS system) was deployed. The SSRS process suggests utilisation of one or more real-time monitoring systems when mining slopes with a high risk classification. In addition to providing monitoring redundancy, the implementation of the second real-time monitoring system (radar) increased monitoring resolution to a level high enough to detect bench-scale slope acceleration as well as facilitate safe remediation of the triple-bench instability on the south highwall.

Given the small to moderate size of the open pit, a monitoring guidance classification of high risk was not initially obvious to the mine operator without consideration of all of the inputs used to determine the $\mathrm{GCl}$ and DPI components of the SSRS. The anticipated blast-induced rock damage combined with design uncertainty contributed to a higher risk rating. It is noteworthy that the triple-bench instability on the southeast highwall accelerated to failure immediately following the trim blast at the toe, validating the assumption that the anticipated blast damage should contribute to a higher risk rating.

\section{Conclusion}

The formative risk-based SMF process, introduced in this paper, is intended to facilitate the design of performance monitoring systems for open pit slopes by means of assessing the likelihood and consequence of slope failure. The SMF process uses three steps to address known and potential slope hazards, assess risks associated with known and potential hazards, and develop a monitoring plan that addresses those hazards. In the case study presented for Pit 1, a high risk ranking was assigned to three of four sectors of the open pit in part due to design uncertainty. Where risk is unknown, or undefined, the authors recommend that risk be considered to be high until potential hazards are identified through assessment of data, stability analyses, and performance monitoring experience.

The experience presented in this paper supports utilising the SMF process as a practical tool that can assist engineers with both the development of appropriate slope monitoring systems and with defining geotechnical risk across open pit mining operations. Modification to the SMF process, such as changing weighting of factors that influence slope stability, can be accommodated by the spreadsheet format. This may be required for specific mining environments. A validation process for each application is suggested.

Slope performance monitoring systems should be designed to address known geotechnical hazards and be capable of conducting adequate surveillance for detection of potential hazards. As risk potential can change during development of a mining operation, so should the monitoring system adapt to those changes, including frequency of measurement and alarming. The SMF process is meant to be employed with engineering judgement, common sense, and periodic review by experienced engineers. 


\section{Acknowledgement}

The authors wish to thank those geotechnical and operations' professionals at the mining operations who supported this project; and to those who participated in a peer review of initial results of trials performed at selected active operations in Nevada, USA. Special thanks are extended to Nevada Gold Mines and to Newmont Corporation for permission to publish this work.

\section{References}

de Graaf, PJH \& Wessels, S 2015, 'Rio Tinto Iron Ore's Pilbara Geotechnical Management System - a framework for managing geotechnical risks across multiple operations with multiple pits', Proceedings of the International Symposium on Rock Slope Stability in Open Pit Mining and Civil Engineering, South African Institute of Mining and Metallurgy, Johannesburg.

de Graaf, PJH \& Wessels, SDN 2016, 'A framework for managing geotechnical risk across multiple operations', Journal of the Southern African Institute of Mining and Metallurgy, vol. 116, no. 5, pp. 367-377.

de Graaf, PJH \& Wessels, SDN 2013, 'Slope monitoring and data visualisation state-of-the-art - advancing to Rio Tinto Iron Ore's Mine

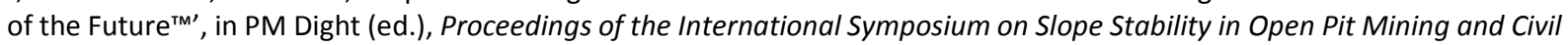
Engineering, Australian Centre for Geomechanics, Perth, pp. 803-814.

Hamman, ECF 2009, 'Qualitative geotechnical hazard and risk assessment', in J Read (ed.), Proceedings of the International Symposium on Rock Slope Stability in Open Pit and Civil Engineering, University de los Andes, Santiago.

Hawley, M \& Cunning, J 2017, Guidelines for Mine Waste and Stockpile Design, CSIRO Publishing, Melbourne.

Hawley, M, Marisett, S, Beale, G \& Stacey, P 2009, 'Performance assessment and monitoring', in J Read \& P Stacey (eds), Guidelines for Open Pit Slope Design, CSIRO Publishing, Melbourne.

Rose, ND, Scholz, M, Burden, J, King, M, Maggs, C \& Havaej, M 2018, 'Quantifying transitional rock mass disturbance in open pit slopes related to mining excavation', Proceedings of the XIV International Congress on Energy and Mineral Resources, Asociación Nacional de Ingenieros de Minas, Seville, pp. 1273-1288. 